\title{
POSCONFLICTO Y LA REVOLUCIÓN DEL ARTE EN LA SOCIEDAD COLOMBIANA
}

\author{
POST-CONFLICT AND THE REVOLUTION \\ OF THE ARTS IN THE COLOMBIAN SOCIETY
}

Julián David García Cárdenas ${ }^{1}$

Resumen

En este artículo se invita a reflexionar sobre el papel de las artes y, en particular, de la danza como una estrategia metodológica, intercultural y recreativa de carácter pedagógico experiencial, que puede ser orientada hacia los procesos que buscan la promoción de la paz, el desarrollo social, la resolución de conflictos, la restauración de derechos o la reconstrucción de la memoria e identidad en Colombia y el mundo. Se parte de un ejercicio de investigación y reconocimiento del conflicto armado colombiano y sus actores, orientado desde la perspectiva de la gerencia social, con una proyección a las víctimas y la afectación que puede tener esta propuesta en ellas.

Palabras claves: posconflicto, violencia, arte, danza, recreación, identidad, gerencia social.

\section{Abstract}

This document is a reflection that invites to think about the role of the arts and more specifically in the dance as a methodological, intercultural, and recreational strategy of pedagogic character based in the experience, that can be oriented to the process that search for peace promotion, social development, conflict resolution, rights restoration, and/or the reconstruction of the memory and identity in Colombia and the world. Stars from an investigation and recognition of the armed conflict in Colombia and its actors, oriented from the perspective of social manager until the projection of the victims and the effects that this proposal may have on them.

Keywords: post-conflict, violence, arts, dance, recreation, identity, social management.

Fecha de recepción: 15 de mayo de 2015

Fecha de aprobación: 16 de septiembre de 2015

Para citar este artículo:

García, J.D. (2015). Posconflicto y la revolución del arte en la sociedad colombiana. Lúdica Pedagógica, (22), 33-43.

1 Candidato a especialista en Gerencia Social. Licenciado en Recreación, docente Universidad Pedagógica Nacional; docente Universidad de los Andes. Correo electrónico: jdwasongar@gmail.com 


\section{INTRODUCCIÓN}

En el presente trabajo se hace un breve análisis soportado en la gerencia social como conceptoy práctica(Serrano,s.f.), de la situación del conflicto armado en Colombia tras décadas de violencia. En principio, es pertinente resaltar algunos puntos. En primer lugar, se debe reconocer que dicho ejercicio considera las profundas indagaciones y estudios previos de esta problemática entre las variables sociales, económicas, políticas y culturales; aquí se ahondará en el estudio de dichas interrelaciones desde una perspectiva de la gerencia social, para lo cual se hará un esbozo de sus fundamentos, elementos, características, etc., y se centrará en los desafíos que implica la reconstrucción en múltiples dimensiones de una nación después del conflicto.

En segundo lugar se incluirán, a buena tinta, algunos aspectos históricos del conflicto armado en Colombia, junto con un recuento sencillo de los distintos acercamientos encaminados a lograr el cese del conflicto armado por parte de los distintos mandatarios de turno. Esto reconociendo el valor de los ciudadanos, las necesidades de los territorios, poblaciones, movimientos sociales, políticos y las víctimas.

En tercer lugar, el estudio se aborda en el marco de un proceso de diálogo y negociación con perspectivas de avance, inmerso en la actual globalización, procurando tener consideración de los elementos aportados desde una perspectiva internacional. Sin embargo, apunta a la libertad política, la intervención ciudadana, la autonomía local y regional, dando lugar a puntualizar en que las principales crisis estructurales generadas por el conflicto armado en Colombia no son exclusivas de las regiones en guerra, sino que se inscriben en una realidad mucho más amplia (Turriago, 2001).

Por último y en consecuencia a esta investigación acción participativa en la educación, se pretende sugerir una serie de reflexiones o conclusiones orientadas por los distintos procesos pedagógicos recreativos y por una gerencia social eficaz y eficiente, a que verifiquen el rol actual del Gobierno en los procesos de reconstrucción, desarrollo identitario y de calidad de vida para las poblaciones afectadas por el conflicto armado. Además, estimar la gestión realizada por los gerentes sociales, cultores, líderes y docentes que a través de la recreación y manifestaciones culturales, específicamente las artes y entre ellas la danza, han rendido sus esfuerzos para llegar al fin del conflicto armado en Colombia y el llamado desescalamiento, que se constituye, entre otras cosas, como lo plantea el siguiente autor:

Desescalar el conflicto no sería otra cosa que las partes decidieran, de común acuerdo, dar cumplimiento estricto a las leyes de la guerra: al estatuto de combatientes, aplicación rigurosa del derecho internacional humanitario y la salvaguarda y aplicación de los Derechos Humanos, entre otras posibilidades del derecho internacional, aplicado al contexto y realidades del conflicto armado colombiano. (Gallego, 2014)

Esta propuesta con el enfoque de investigación acción participativa en la educación (Flores, Montoya y Suárez, 2009) va enfrentando el desafío de generar conocimiento con los actores sociales afectados, que vivencian la realidad del conflicto armado en Colombia y que por medio de la danza y la gerencia social pueden asumir el poder de transformarse creativamente.

\section{UN ACERCAMIENTO AL CONFLICTO ARMADO EN COLOMBIA DESDE LA GERENCIA SOCIAL}

El hecho de describir la historia, las principales crisis estructurales dadas por el conflicto, el contexto violento en el que se ha desarrollado Colombia en las últimas cinco décadas, los procesos de paz y reconciliación, el papel del Estado y la administración pública, pueden ser el reflejo de un ambiente vehemente y doloroso, esto implica forjar una lectura crítica, objetiva y que se pueda definir y puntualizar. En consecuencia, se comienza por identificar el campo de la gerencia social y su pertinencia en la resolución del conflicto, el acercamiento a la reconciliación, el fortalecimiento de la identidad y la construcción de la paz.

Esta temática presentada en la década del noventa, entre otros por el Instituto Interamericano para el Desarrollo Económico y Social (INDES), despliega una concepción de la gerencia social como un campo que aporta al desarrollo de los países latinoamericanos, desde el análisis, la discusión y la proyección de políticas públicas.

Después de estudios e investigaciones enmarcados en problemas de la región, junto con desafíos sociales y propuestas de desarrollo social, se presentan como consideraciones para el abordaje de la gerencia social cinco premisas básicas por parte del Banco Interamericano de Desarrollo (2006): 
- Particularidades de la gerencia social INDES.

- Formación de políticas y programas sociales.

- Articulación de las políticas económicas, sociales y el desarrollo institucional.

- Provisión de servicios sociales a través de una gestión de resultados.

- Importancia asignada a la dimensión ética del gerente social. (p. 5).

Estas se plantean con el fin de aportarles a los gerentes sociales las capacidades y herramientas para afrontar las dinámicas de creación, gestión y promoción de políticas y proyectos sociales. Además, se sugiere un conjunto de objetivos o criterios guía, que evidencian y fundamentan este proceso de formación, gerencia y evaluación de estos programas sociales que apunten siempre a la equidad, eficacia, eficiencia y sostenibilidad (Mokate, 2001). Fines orientados a reducir la desigualdad y la pobreza.

El BID presenta enfáticamente una articulación entre el análisis, la discusión y la ejecución de las propuestas, políticas y proyectos planteados por la sociedad y por los gerentes sociales, para desarrollar el concepto de valor público como fortalecimiento de la ciudadanía, el crecimiento económico y el mejoramiento en la calidad de vida de las poblaciones vulnerables e históricamente excluidas de América Latina (Kliksberg, 1996).

Siendo un campo relativamente nuevo, pues desde finales de los años 1980 se empiezan a reconocer organizaciones constituidas que trabajan por el fortalecimiento y el devenir de las propuestas o proyectos sociales, esta temática genera ciertos planteamientos que caracterizan el estudio, la investigación y la ejecución de métodos y estrategias, con la intención de afectar positivamente los programas sociales que promueven el mejoramiento de la calidad de vida. Siendo la gerencia social también el objeto de estudio la formación de especialistas que identifiquen, propongan, diseñen o re-creen proyectos de forma exitosa.

Es importante concebir la complejidad del contexto social colombiano - pasando por la comprensión de las tendencias mundiales, de la transformación del capitalismo como crisis estructural, de los modelos de organización social, los modelos de desarrollo, las transformaciones permanentes del Estado, la política pública social y los procesos de planificación del desarrollo-, para aportar herramientas conceptuales, teóricas y técnicas en aras de que los profesionales puedan interpretar, analizar y conocer las relaciones entre la problemática del desarrollo social y la gerencia social; el papel del Estado y el gobierno como garantes de los derechos humanos, económicos, sociales y culturales de la población. De esta manera, el gerente social estará en capacidad de proponer y diseñar estrategias de solución que contribuyan al desarrollo social.

\section{DIÁLOGOS Y NEGOCIACIONES PARA EL CESE DEL CONFLICTO ARMADO}

Hay que tener en cuenta que este conflicto surge en la segunda mitad del siglo xx de la violencia bipartidista, donde se ven enfrentados los grupos guerrilleros de extrema izquierda y grupos paramilitares de extrema derecha, además del Gobierno, en su búsqueda de poder político, económico y territorial.

Para entender esta situación, se deben identificar sus causantes. En principio se puede determinar la disputa por la tierra y el problema agrario, siendo este uno de los focos principales para que el conflicto continúe. Es constante, como hecho violento, la falta de garantías para la participación política, lo que desencadena la limitación del acceso de distintos grupos y un óptimo ejercicio democrático del país.

El narcotráfico, por su parte, se da también como causa principal; mediante este acto delictivo los grupos guerrilleros han conseguido parte de los recursos económicos para mantenerse activos; sin dinero no hay guerra. De aquí se origina la expansión del movimiento guerrillero que, además de generar un impacto cultural, creó nuevas rutas de acceso social, con lo cual se dejó al país vivir una época en la que no importaban los medios para conseguir dinero, y se da así el establecimiento de la violencia, convirtiendo al país en un Estado con poca moral y mucha deslegitimación.

Los alicientes al conflicto vienen dados dentro de un marco de permisividad estatal, políticas públicas mal direccionadas, necesidades básicas insatisfechas, inicua distribución de la tierra, inestables procesos de reparación de víctimas y discriminación que imposibilitan el reconocimiento explícito del verdadero efecto que esto tiene sobre la población. La victimización de la población civil es la principal estrategia de los actores del conflicto 
interno: masacres, asesinatos selectivos, genocidios, el reclutamiento forzoso y las amenazas directas son solo unas de las prácticas más comunes de los grupos irregulares como táctica para atemorizar, apropiarse de recursos públicos, usurpar tierras fértiles e invadir terrenos con localización estratégica (fronteras o lugares con inasistencia institucional). (Ibáñez, 2011)

Colombia ha sufrido devastadores momentos, tanto por la guerra - el propio país es culpable de permitirles a grupos ilegales desarrollarse por más tiempo de lo esperado-, como por el retraso sistemático de la nación frente a potencias latinoamericanas, el hecho de no reconocer el valor que tienen las poblaciones $y$ comunidades que por décadas han sido afectadas y la negación del valor cultural perdido o arrebatado; este último reemplazado por una cultura de desconocimiento y conformismo encaminado en una vida en la que aún no se espera que este conflicto acabe, da una presión mundial de la globalización en distintos contextos para el país. Esta presión se convierte en un motor más del conflicto armado, ya que al vivir la lucha contra el terrorismo se pretende el desarrollo. Este hecho genera unos descuidos y una toma de decisiones no concienzudas.

Es debido a esa imposición que se deja de lado la necesidad de técnicas de contención y de formación de alta calidad pensando en la particularidad de cada población, creando un estado de desbalance interno en el país, con lo cual se da paso a la corresponsabilidad internacional con respecto al conflicto armado colombiano; aunque no hay que olvidar que también existieron técnicas históricas de contención y represión internacional en contra del conflicto.

Pensar en la reconciliación como una manifestación de reconocimiento y acercamiento escalonado de narrativas opuestas (Orozco, 2003), es una situación en la que se ubican culpables e inocentes en un mismo escenario, en una categoría en la que se puede ser víctima y victimario; por consiguiente, se constituye en un escenario en el que se puede bajar la carga negativa gracias a los puntos en común. Brounéus (2003) afirma que la reconciliación es un "proceso social que involucra el reconocimiento mutuo del sufrimiento pasado, y el cambio de actitudes y comportamientos destructivos por relaciones constructivas para una paz sostenible" (s.p.).

El posconflicto, definido como un periodo claramente identificable, consecutivo a la superación total o parcial de los conflictos armados, puede comprenderse como "un concepto de un único atributo: la reducción del número de homicidios relacionados con el conflicto por debajo de un umbral determinado, que le otorga o le niega el estatus de conflicto activo" (Experimentos sobre reconciliación política en Colombia, s.f.). Transgredir entonces desde la reconciliación y el posconflicto colombiano es una mirada hacia el futuro; es un proceso de creación de mecanismos de paz para buscar alternativas, para transformar y terminar con la violencia. Así se analizaría un proceso de paz, donde se emplee la reconciliación social, donde sean los mismos pobladores quienes participen de esos procesos tan importantes para superar esta situación, siendo fundamental que ellos puedan pensar, discutir, describir, narrar, confesar lo que les sucedió, con el fin de apropiarse de las herramientas y de los contenidos.

Sentarse a jugar, a discutir en una misma mesa con personas que quizás comparten historias similares, es parte de una propuesta innovadora y transformadora que tendría como fin hablar de la tragedia para superarla.

En Colombia se han llevado a cabo procesos de paz durante años, muchos de ellos logrando beneficios, en otros no tanto, pero para todos la paz ha sido esquiva de obtener. El primer acuerdo firmado fue bajo el gobierno de Gustavo Rojas Pinilla (1953-1957) con la intención de indultar los alzados en armas, pero esto no tuvo mayor beneficio, ya que fueron asesinados algunos reinsertados, hecho detonante para el resto de los insurgentes. Luego empieza la era sin tregua para el país y el conflicto interno; aunque a finales de los años 1980, el M-19 se desmoviliza y se crea una esperanza para alcanzar la paz. Con el gobierno de Andrés Pastrana (1998-2002), se lograron acuerdos, pero no hubo gran resultado debido a que el país tuvo una época de mucha violencia, crímenes de secuestro, "el collar bomba" (Revista Semana, 2015), el secuestro del avión de Satena, entre otras cosas, que dejaron a la nación con pocas perspectivas en los acuerdos de paz.

En el periodo del expresidente Uribe Vélez (2002-2006) se dieron otros resultados con su política de mano firme para hacerle frente al conflicto, con la cual se obtuvo un acuerdo en la zona de concentración de autodefensas, pero desplegándose una oleada de delincuencia común según la Organización de Estados Americanos (OEA) con la conformación de las denominadas bandas criminales emergentes (Bacrim). En la actualidad, con el gobierno de Juan Manuel Santos, quien dice poseer las llaves para 
la creación de la paz, se siguen conversaciones en La Habana; aun así, se reitera el papel de todos los actores con el deber y el derecho de opinar para poder articular todos los esfuerzos.

En el actual gobierno se han desarrollado por más de dos años y medio, reuniones en La Habana, Cuba, discutiendo y logrando acuerdos para ponerle fin a la guerra entre las Farc y el Estado. El presidente Santos ha dicho lo siguiente en la alocución del 4 de septiembre de 2012, sobre el acuerdo general para la terminación del conflicto:

Un proceso para terminar el conflicto en mi gobierno solo sería posible si este sigue tres principios: aprender de los errores y aciertos del pasado para no crear falsas expectativas; lograr efectivamente el cese del conflicto -no su prolongación-, y no ceder un sólo milímetro del territorio nacional. (Presidencia de la República, 2013)

Los diálogos de paz en la Habana comienzan por medio de unos discursos que delimitan el cronograma de negociación: para el Gobierno era incuestionable en la mesa de negociación el modelo de desarrollo económico, el modelo de Estado y la doctrina militar ("Declaración del jefe", 2015). De forma alterna, el desarrollo agrario, el narcotráfico, la participación política, la dejación de armas como fin de la guerra y las víctimas ("Documento oficial del proceso de Paz en la Habana, Cuba", 2015) fueron los temas propuestos y aceptados por las partes. A su vez, el Gobierno, mediante el legislativo:

[...] construyó y aprobó un marco jurídico para la paz con el fin de poner condiciones en la negociación dentro del contexto de la justicia transicional, los parámetros de la justicia internacional como la Corte Penal Internacional y los derechos humanos.

(Presidencia de la República, 2015)

No todo el proceso de paz en el territorio nacional ha sido como lo ha matizado el Gobierno, ya que se ha visto afectado con episodios de violencias en distintas zonas del país. Buenaventura ha sido objeto de violencia del conflicto, donde se ha divisado una ola de amenazas contra el pueblo con los cuerpos desmembrados, dando muestra de la violencia que se vive en las calles, aumentando el número de desaparecidos y la crisis humanitaria que sufre la comunidad. Aquí no se ha visto al Estado y se ha movilizado a muchas personas, los jóvenes en represalias han creado nuevos grupos en contra. Por otro lado, en Tumaco se presenta una situación similar, en la cual se ha visto un incremento de hechos delictivos, personas desaparecidas y violaciones; las Farc y los grupos paramilitares son causantes de esta situación y además son los responsables del secuestro de niños para enfilarlos en sus causas y sembrar terror en estas y otras comunidades.

Debido a que la violencia de género ha sido parte de este gran problema, para lograr el camino de la paz colombiana se ha reforzado el papel de la mujer con un alto valor e importancia. Las mujeres representan esa esperanza y fuerza para darle fin al conflicto.

En algunas dinámicas de poder, por ejemplo, se busca denigrar su figura, siendo tratada como botín para desmantelar a los contrarios y mostrada como la debilidad y fragilidad que puede ser quebrantada en cualquier momento. Estos hechos son algunos de los principales actos en los que se ha utilizado el rol y la vida de la mujer como un medio para conseguir un fin, también se ha afectado a la mujer en general de otras formas directas fuera de los atentados contra su ser, amenazando a sus familias y por medio del reclutamiento forzado, dejando de lado los derechos humanos sin importar que dejen ultimados baños de sangre y demás hechos delictivos para domesticar la sociedad misma. Las mujeres, dentro de esta situación social, buscan construir y suplir las carencias del Estado Social de Derecho frente a los conflictos, aportando a una nueva construcción desde las mismas comunidades mediante movimientos sociales colectivos, haciéndole frente a la pobreza, la corrupción y cualquier tipo de violencia.

Ahora bien, hay que reconocer que fuera de las filas armadas ilegales se han reintegrado un sinnúmero de guerrilleros a la vida civil, aún no podemos decir que lo hayan logrado de forma efectiva en la sociedad, puesto que para crear una nueva vida y llegar a tener una aceptación social, principalmente deben cumplir con una serie de condenas y reparaciones que son efecto de sus actos terroristas.

Ellos deben seguir el programa de reintegración de la vida civil del Ministerio del Interior, quienes son los encargados de evaluar la situación haciéndose cargo de los desmovilizados y crear un contacto entre estos y sus familias. Aquí empieza ese proceso de reintegración social. Primero se debe cumplir una condena de varios años en prisión, según lo establecido en la Ley de Justicia y Paz (Oficina del Alto Comisionado para la Paz, 2005), esto dado a la colaboración con el Gobierno 
y abrir nuevos campos de justicia con la sociedad. Este programa busca fortalecer la implementación de esta política de reintegración, brindando la atención psicosocial, de servicio y beneficio para las personas desmovilizadas, con el fin de llevar a cabo la reinserción social tanto en el corto como en el largo plazo. Tiene como objetivo educar a los desmovilizados, mediante la implementación de estrategias para crear un concepto de sostenibilidad para que lleven una vida civil como cualquier colombiano, garantizando así la continuidad y fortalecimiento de la política de reintegración social.

Dentro del proceso de reintegración, de reparación y reconstrucción, se podría pensar en las artes como recursos que inciden en el momento de transición por el que está pasando el conflicto armado en Colombia; en otros términos, se hace referencia a la creación de nuevas experiencias que permitan mitigar el impacto humanitario entre el conflicto y su finalización. En conjunto, la paz en Colombia se puede valorar como una estrategia metódica, social e innovadora que daría respuestas efectivas a las necesidades de la población, a la participación ciudadana, la justicia social y la equidad para adelantar trabajos colectivos en el seno de las comunidades mayormente afectadas. La paz recrearía vínculos nuevos, cerrando los pasados llevados por el conflicto y situaciones abusivas del poder, el arte tiene un trasfondo demasiado emotivo, ya que en general posee un sin número de expresiones y sabores que hace que se convierta en un medio que puede contribuir en una diversidad de maneras únicas y sensibles.

La implementación de las artes como actividad recursiva ha justificado su potencial en la transformación de las sociedades, y desde los gerentes sociales, educadores, recreadores, gestores culturales, grandes sabedores de las regiones, líderes comunitarios y de proyectos, se robustece el tejido social con iniciativas en danza, teatro, música, literatura, pintura y otras artes, las cuales son herramientas para el cambio. Así se limitan las situaciones y mensajes sobre la violencia social, y las expresiones artísticas se constituyen en una respuesta en contra de la guerra, la crueldad, la sangre y traumas que han dejado este conflicto interno. Se debe saber que el arte es ese reflejo propio de las situaciones en que se vive un contexto social, político, histórico y religioso de quien lo practica, ya que son expresiones que van desde el fondo de quien lo implementa, todo esto impulsado por sus creencias y sentimientos, aquello que quiere dar a conocer sin la necesidad de mencionar y actuar de una forma revolucionaria tradicional.

\section{EL ARTE DISMINUYENDO PAULATINAMENTE LA VIOLENCIA}

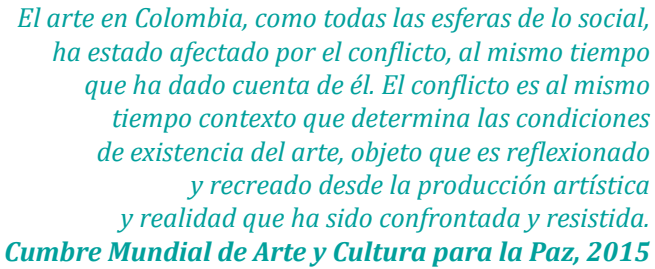

El arte en Colombia, como todas las esferas de lo social, ha estado afectado por el conflicto, al mismo tiempo que ha dado cuenta de él. El conflicto es al mismo tiempo contexto que determina las condiciones de existencia del arte, objeto que es reflexionado y recreado desde la producción artística y realidad que ha sido confrontada y resistida. Cumbre Mundial de Arte y Cultura para la Paz, 2015

Estudiando esta disciplina académica como una técnica para minimizar la capacidad de destrucción que se ha desarrollado por años en el país, se ha logrado trabajar esa construcción de la paz realizando distintas propuestas para prevenir y resolver distintas problemáticas, involucrando una situación de entendimiento, de identidad, de restauración de derechos, de mejorar la comunicación y resolver diferencias.

Es imperativo recordar que la cultura se encuentra consagrada en la Constitución Política de Colombia de $1991^{2}$, y es parte esencial de los derechos humanos. La participación de la vida cultural comienza de esa diversidad de comunidades así como de individuos en la sociedad, creando varios caminos de comunicación e integración, con lo cual se logra una memoria colectiva, se enriquecen las culturas en cualquier zona del país, y se nutre esa sociedad que se ha visto dañada por décadas de conflicto. Sin duda, es un medio para recordar todos los errores del pasado, pero nos muestra qué es a lo que no queremos volver. La cultura mediante el arte tiene un acceso libre, con gran disponibilidad y facilidad para cualquier participante de la sociedad, ya que no importa su edad, sus ingresos y demás factores, pueden pertenecer a este espacio de alimentación del alma cultural, como medio de vitalización de pensamiento y ánimo, ya que ayuda a expresar y sacar todo lo que se piensa y se siente.

2 En especial los artículos 7: "El Estado reconoce y protege la diversidad étnica y cultural de la nación colombiana"; y 67: "La educación es un derecho de la persona y un servicio público que tiene una función social; con ella se busca el acceso al conocimiento, a la ciencia, a la técnica, y a los demás bienes y valores de la cultura". 
En la Constitución Política Colombiana se expresan dichos derechos; por ejemplo, el artículo 71 declara la libertad en la búsqueda de conocimiento y expresión artística, ya que de aquí se establece que los planes de desarrollo deben tener en cuenta el fomento tanto en ciencia como en cultura. También el artículo 70 señala que es una obligación del Estado promover estas prácticas, pues el acceso a la cultura debe ser para todos los individuos de la sociedad colombiana en igualdad de condiciones. Por esto se puede determinar que Colombia cuenta con un respaldo constitucional cuando se habla de cultura y sus derechos humanos culturales, respaldo que permite avanzar en la implementación de herramientas constitucionales a favor de prácticas culturales.

¿Cómo se puede traspasar esa cadena de hechos violentos que se ha vivido en el país por varias generaciones? La respuesta, sin desconocer los múltiples factores determinantes en la postergación del conflicto y el sinfín de opciones y recursos que están siendo ejecutados desde distintos ángulos, es parte de una forma alternativa y significativa con la gestación de programas y proyectos de arte, ya que no es solamente entender el motivo o la causa para que se creara la violencia colombiana, sino el recrear y emprender un camino nuevo gracias a la imaginación y a la creatividad para escapar de ese círculo vicioso que ha sido creado. Este ámbito es tan esencial para enseñar a convivir con ese antagonista, pues se trata de llegar a un empalme de ideas, pero siguiendo una vía de comunicación entre los involucrados, permitiendo crear y establecer nuevas relaciones para ir más lejos y profundo en las ideologías y pasiones humanas.

Así, se quebranta la tradicional dicotomía entre conceptualización/diseño y ejecución/implementación al equipararlas y articularlas estrechamente. Una conclusión de lo anterior es que se realza la importancia de la implementación, teniendo en cuenta al individuo y sus intereses, pero también se le da relevancia a la fase de selección de opciones, un componente generalmente olvidado en el ciclo de las políticas y programas. Proponer que esta fase sea igualmente incluyente y que el proceso de decisiones articule los intereses de todos los actores involucrados, especialmente de los tradicionalmente excluidos, da un valor agregado al propósito de avanzar en la democratización de las políticas públicas (Banco Interamericano de Desarrollo, 2006).
La participación de la población debe tenerse en cuenta a lo largo de todas las fases de los planes y proyectos; es decir, además de considerar sus aportes en la etapa de formulación, es importante que participen en su implantación y evaluación para que así tengan más sentido de pertenencia y controlen su ejecución, siendo a su vez veedores del proceso. El verdadero cambio y la eficiencia en proyectos de desarrollo está en formar líderes y comunidades conscientes de la problemática social, identificación de necesidades, creación de valor público y responsabilidad ética para una participación activa en la formulación, ejecución seguimiento y evaluación de los mismos. De acuerdo con lo planteado por Mokate y Saavedra (2005), es necesario que se fortalezcan los instrumentos para proponer y explorar nuevas metodologías de liderazgo dentro de los diferentes estamentos regionales, para que el diálogo sea una fuerza primordial para la ejecución de los planes de desarrollo.

La ciudadanía expresa a través del proceso político democrático sus preferencias acerca del valor que debería producirse. Es decir, se expresa no solo sobre el valor público, sino también sobre ciertas dimensiones relacionadas con el valor privado que los clientes deben consumir.

La ciudadanía es una colectividad; es una membresía en una comunidad nacional. Ello conlleva derechos y responsabilidades. La opción colectiva no significa la agregación de preferencias de los ciudadanos individuales. Las opciones colectivas son necesariamente el resultado de interacciones y deliberación política. El procedimiento es aquel en que, supuestamente, se reflejan las preferencias de la mayoría, identificadas o estimadas de manera más o menos válida. (Mokate y Saavedra, 2005, p. 12).

Se puede afirmar que las expresiones culturales derrochan emoción y sentimentalismo para transgredir y estremecer sociedades completas, lo cual también permite reconstruir elementos comunes en conjunto; ayuda a levantar, rehacer y reconciliar esa unidad nacional. El arte es una herramienta para relacionarse de forma positiva y crear un ambiente propicio de armonía entre sus integrantes. La paz se convertiría entonces en un camino real, ayudado por el arte y demás propuestas transversales encaminadas a lograr ese objetivo, que mitiguen las acciones en contra de las comunidades. A la vez facilitaría implementar una política emocional para crear cultura mediante actos simbólicos y manifestaciones comunes. 
La danza puede surgir como ese método para compactar lo idealizado con el cuerpo, pues "nos permite hablar de la sevicia con la que nos hemos ensañado con el cuerpo, cómo lo hemos convertido en arma y territorio de guerra" (Restrepo, 2013, s.p.); por tanto se crea un pensamiento y sentimiento completo del individuo. Esto ayuda a la percepción de la unidad personal y mental, ya que la danza es un medio para articular los procesos cognitivos, corporales y emocionales, a la vez que aporta a la buena salud de las personas, sin olvidar esa posibilidad de cambiar experiencias poco gratas.

Implementar la danza como terapia es una estrategia que tiene en cuenta al cuerpo como poseedor de una memoria propia; el movimiento es la representación de las emociones junto con la música implementada, creando así experiencias únicas cargadas de emociones que emiten la personificación en escena o en las comunidades, ayuda a que se integren esas piezas fuera del camino mediante la adaptación y la comunicación no propiamente hablada. Es una composición de movimientos, posturas y respiraciones para crear un perfecto balance en la interpretación del mensaje, haciendo valer cada una de las herramientas corporales para la explotación de recursos comunicativos, de eso que se vivió o se recuerda para superar etapas crudas de la vida pasada.

Las técnicas que envuelven la danza pretenden, entre otros objetivos, llevar el sentimiento interno a una proyección en el exterior, permitiendo una elección en el tipo de baile de acuerdo a los sentimientos guardados. Cabe resaltar que aunque sean pequeños movimientos o gestos, estos pertenecen a ese mundo exterior, generan un valor agregado, brindan seguridad a la persona y un fortalecimiento de su propio carácter. En la danza como proceso pedagógico se emplea ese elemento conocido como mimesis, o imitación, con el cual se intenta conectar esa percepción inmediata para comparar o aceptar la información suministrada por otro, creando un vínculo y aceptación de sentimientos con esa otra persona o grupo.

Al mismo tiempo, la danza puede darse mediante un proceso de improvisación, el cual puede estar más lleno de sentimentalismo, en el momento, que cualquier otra manifestación. Por lo general no tiene una preparación —lo que se denomina impulso-; es decir, la persona quiere demostrar lo que desea, y lo realiza representándolo mediante movimientos esporádicos, reacciones, solo sintiendo. Dejando en claro, al menos para el intérprete, sus pensamientos y vivencias con ayuda del movimiento. Esto puede ser presentado como una problemática al no percibir los limites en cuanto a la creatividad, pero también una posibilidad infinita, pues simplemente se da un juego desde los movimientos propios del individuo, utilizando esa conexión para despertar emociones y dejarse llevar por estos para así poder soportarlos e incluso superarlos.

De aquí que la creación de la danza sea una combinación y un proceso de identificación de expresiones emocionales que enmarcan momentos reales o lo que se quiera proyectar, una posibilidad de comunicarse y hacer uniones en comunidades desde su seno gracias a la experiencia propia que brinda el arte. Por esta razón, se conoce como un medio que logra grandes movilizaciones, siendo este uno de los muchos argumentos para ser implementados en contra de la violencia y construir esa anhelada paz en Colombia.

\section{CONCLUSIONES}

Este ejercicio de investigación ha llevado a conclusiones dadas por las propuestas teóricas, que tuvieron en cuenta distintos autores entorno al posconflicto, la danza y el arte. Se proyecta, desde estas, una propuesta pedagógica y de entretenimiento con un trasfondo lleno de comunicación y cargado de emociones.

La representación artística es ese dispositivo didáctico que propicia la reintegración a la sociedad civil y un medio pacifista revolucionario para mostrar eso que se piensa sobre la realidad, logrando así dramatizar la historia y a la sociedad misma que inició esta problemática. Es claro que los medios indicados para mostrar la ansiedad e inconformidad pueden ser estos, ya que comunican lo que realmente se quiere lograr si se maneja de forma correcta. El arte es una herramienta poderosa para re-crear alternativas que demuestren las visiones e ideologías que se tiene del mundo, con ellas se pueden cambiar las formas de enfrentar la inconformidad.

El arte, si se lo propone, puede llegar más allá de lo que un diálogo puede conseguir, dado que las palabras sin actos no son grandes muestras de que se quiera un cambio; por su parte el arte está cargado de acciones que logran expresar lo que se quiere decir y se siente en verdad, es una trasmisión de sentimientos que ayuda a superar los enfrentamientos y a crear esa reconciliación 
que se está buscando desde hace varios años. Ayuda así a las instituciones a ofrecer mecanismos de reducción de la violencia, recurriendo a medios que ayudan a los conflictos sin necesidad de agresiones, rompiendo lo que antes conocíamos como un medio de hacer valer pensamientos e ideologías. A la vez, confiere una responsabilidad al Estado para que resignifique y reevalúe todos los recursos que invierte en la guerra, hacia dónde los debe encaminar y cuáles serán las poblaciones con mayor necesidad de intervención y apoyo.

Es claro que el arte es una cura para el sufrimiento que llevan las personas y un medio, algo superficial pero vital, para aquellos que lo utilizan como medio de autoexpresión o como estrategia para superar etapas graves. El arte contiene así, grandes significados para las comunidades, resolviendo conflictos con nuevas expresiones de comunicación. Es una apuesta de generación de sujetos políticos que apela incluso a la educomunicación.

La educomunicación concibe el aprendizaje como un proceso creativo donde solo es posible la construcción de conocimientos a través del fomento de la creación y la actividad de los participantes. El conocimiento no es algo dado o transmitido sino algo creado a través de procesos de intercambio, interacción, diálogo y colaboración. La educomunicación debe favorecer este tipo de dinámicas de aprendizaje donde la creatividad es, al mismo tiempo, objetivo y método en procesos de análisis y experimentación permanente. (Coslado, 2012, s.p.)

El mundo del arte ofrece muchas posibilidades para explorar, refiriéndose al trasegar del tiempo y a las soluciones de conflicto, ayuda a tener esa transformación de comunidades mediante las formas de comunicación, dejando a un lado expresiones violentas con la ayuda de experiencias emocionales transformadoras, creando nuevas sociedades unidas por la pasión de crecer juntas, interpretando lo que se quiere lograr desde una perspectiva totalmente diferente a lo que se refiere la violencia y el acto delictivo. Las artes se pueden convertir en esos escenarios de reunión para las comunidades en donde se intercambien experiencias, saberes, historias, costumbres, donde haya un acceso a un mundo de posibilidades infinitas.

La danza tiene unas peculiaridades en cuanto al arte que la hace más fácil de trabajar con poblaciones vulnerables y con personas que tienen el propósito de restaurar sus derechos, pues es una práctica que se encuentra instau- rada en el imaginario cultural de las comunidades, ya sea desde los desfiles, ferias, carnavales, celebraciones e incluso rituales religiosos, dándoles la posibilidad inclusive a personas que no se conocen que están reunidas compartiendo desde la diferencia y la diversidad a que potencien el valor de sus prácticas comunes, generando en sí una recordación de cuáles son sus tradiciones, sus costumbres, sus bailes y cómo estos se constituyen en un derecho fundamental de todos.

Desde la recreación y la gerencia social se postula a la danza como una estrategia metodológica de enseñanza y aprendizaje orientada a la resolución de conflictos, la reconciliación, a la restauración de los valores, los derechos culturales, la reconstrucción de la identidad y el reconocimiento de los saberes diversos.

Entonces, se parte de una práctica artística que posibilite pensar y reflexionar el movimiento, el juego, la ronda, la danza tradicional; la danza es un espacio académico que se propone generar un ambiente pedagógico de reflexión colectivo, un diálogo de saberes en torno a la relación entre desarrollo social, la política social y los planes para comprender la planeación del desarrollo social, analizar el papel del Estado, de las políticas públicas y de los actores sociales involucrados en el conflicto. El propósito es reflexionar acerca del papel de la gerencia social y la recreación, enfrentar la deuda social y la pobreza cuyos índices se han disparado, para así, elaborar y recrear una propuesta más contemporánea de lo que somos, de las situaciones ya vividas que fortalecen el presente y proyectan el futuro.

La propuesta pretende aclarar y reconocer la condición de ser víctima del conflicto armado en Colombia, el hecho del desplazamiento forzoso como uno de los efectos más graves producidos por ese conflicto, aclarando que no puede ser una categoría que generaliza y enmarca una situación común para todos los afectados, pero sí una propuesta que debe tener en cuenta los niveles de calidad de vida, el asentamiento, su origen, la reconstrucción de su identidad. Es la danza reflexionada por la misma comunidad, que participa y trabaja desde el sentir del territorio, para el territorio y con el territorio, en donde las poblaciones deben ser las guías de este programa para superar su propia situación. La sanación es parte esencial del proceso y tiene como fin un empoderamiento de los contenidos y las herramientas, destacando que con o sin palabras se puede hablar de la tragedia para superarla. 
El arte como testimonio durante la guerra es diferente del arte de la guerra. No obstante, existe un momento en que estas dos modalidades se reúnen: cuando un artista toma las armas, se compromete con uno de los grupos en conflicto y, si bien como soldado lucha por una ideología, como artista produce obras que van más allá del simple documento. (González, 1938, s.p.)

La danza se convierte entonces en ese elemento crucial en el cual se interpreta lo que se siente, se teme y se anhela; incluso, con la reparación desde la base de las sociedades se puede pensar en cómo es el individuo creando esa transformación de sus condiciones actua- les, asentamientos, reconstrucción y resignificación de su identidad, territorio y memoria colectiva. La danza, como manifestación de cambio a través de procesos sencillos pero prioritarios, permite entender la diversidad colectiva y las dinámicas propias de cada contexto, todo compuesto gracias a la conexión entre cultura, tradición, mente, cuerpo y movimiento, mediante reflejos armónicos perceptibles y cargados con emociones internas, convirtiendo esto en voces diversas para la implantación de nuevos pensamientos y una época de cambio, encaminada a la paz del país.

\section{REFERENCIAS BIBLIOGRÁFICAS}

Banco Interamericano de Desarrollo (2006). La gerencia social INDES. Washington.

Brounéus, K. (2003). Reconciliation. Theory and practice for development cooperation. Estocolmo: Documento SIDA.

Coslado, A.B. (2012). Educomunicación: desarrollo, enfoques y desafíos en un mundo. Foro de Educación, (14), 157-175.

Cumbre Mundial de Arte y Cultura para la Paz. (2015). Recuperado de http://www.idartes.gov.co/index. $\mathrm{php} /$ programas/cumbre-mundial-arte-y-culturapara-la-paz

Documento oficial del Proceso de Paz en La Habana, Cuba (2015). Acuerdo General para la terminación del Conflicto y la construcción de una paz estable $y$ duradera. Recuperado de: https://www. mesadeconversaciones.com.co/sites/default/files/ AcuerdoGeneralTerminacionConflicto.pdf

El collar del terror (29 de mayo de 2015). Recuperado de: http://www.semana.com/nacion/articulo/el-collardel-terror/42339

Experimentos sobre Reconciliación Política en Colombia. (s.f.). Posconflicto. Recuperado de: http://www. urosario.edu.co/jurisprudencia/jurisprudenciareconciliacion/ur/Postconflicto/

Flores, E.; Montoya, J. y Suárez, D.H. (2009). Investigación acción participativa en la educación latinoamericana: un mapa de otra parte del mundo. Revista Mexicana de Investigación Educativa, (14). [En línea]. Recuperado de: http://www.redalyc.org/articulo. oa?id=14004013> ISSN 1405-6666
Gallego, C.M. (3 de diciembre de 2014). ¿Qué significa desescalar el conflicto armado? Recuperado de: http:// www.las 2 orillas.co/que-significa-desescalar-elconflicto-armado/

González, B. (1938). Artistas en tiempos de guerra: Peregrino Rivera Arce. Recuperado de http://www. banrepcultural.org/blaavirtual/todaslasartes / artiegue/artiegue $0 . h t m$

Ibañez, A. M. (2009). El desplazamiento forzoso en Colombia: un camino sin retorno hacia la pobreza. Bogotá: Kimpres.

Kliksberg, B. (1996). Hacia una gerencia social eficiente. Algunas cuestiones clave. Revista Mexicana de Ciencias Políticas y Sociales 44(175), 15-29.

Mokate, K.M. (2001). Eficacia, eficiencia, equidad y sostenibilidad:¿qué queremos decir? Washington: Inter-American Development Bank.

Mokate, K. y Saavedra, J.J. (2005). Gerencia social: un enfoque integral para la gestión de políticas y programas sociales. Washington: Banco Interamericano de Desarrollo, Instituto Interamericano para el Desarrollo Social.

Oficina del Alto Comisionado para la Paz (2005). Ley de justicia y paz. Bogotá.

Orozco, I. (2003). La posguerra colombiana: divagaciones sobre la venganza, la justicia y la reconciliación. Hesburgh: Helen Kellogg Institute for International Studies.

Presidencia de la República (2013). Declaración del jefe de la Delegación del Gobierno en la mesa de 
conversaciones, Humberto de la Calle. Recuperado de: http://wsp.presidencia.gov.co/cepri/noticias/2013/ abril/Paginas/20130430_04.aspx

Presidencia de la República (2015). Acto Legislativo No. 01 del 31 de julio de 2012. Por medio del cual se establecen instrumentos jurídicos de justicia transicional en el marco del artículo 22 de la Constitución Política y se dictan otras disposiciones. Recuperado de: http://wsp.presidencia.gov.co/ Normativa/actos-legislativos /Documents/2012/ ACTO\%20LEGISLATIVO\%20N\%C2\%B0\%2001\%20 DEL\%2031\%20DE\%20JULIO\%20DE\%202012.pdf.

Presidencia de la República (4 de abril de 2012). Alocución del Presidente de la República, Juan Manuel Santos sobre el 'Acuerdo General para la Terminación del Conflicto'. Recuperado de: http://wsp.presidencia.gov.co/ Prensa/2012/Septiembre/Paginas/20120904_01. aspx

República de Colombia (1991). Constitución Política de Colombia. Bogotá: Leyer.
Restrepo, A. (17 de diciembre de 2013). Víctimas de conflicto colombiano cuentan su drama en espectáculo de danza. Diario El Espectador.

Revista Semana (29 de mayo de 2015). El collar del terror. Recuperado de: http://www.semana.com/nacion/ articulo/el-collar-del-terror/42339

Sanabria, A. (s.f.). Los derechos culturales en Colombia. Recuperado de: http://www. culturarecreacionydeporte.gov.co/portal/sites/ default/files / 2.\%2 0 Lectura \% 2 01\%2 0 - \% 20 Derechos\%20culturales\%20en\%20Colombia.pdf

Serrano, A.O. (s.f.). Conceptos de la gerencia social en América Latina. Bogotá: Corporación Universitaria Minuto de Dios. Recuperado de: http://proyectosocial. unizar.es/n16/06-\%200rtiz.pdf

Turriago, J.C. (2001). Integridad territorial y paz: hacia un ordenamiento democrático. En: Garay, L.J. (Coord.). Hacia el nuevo pacto social (pp. 83-100). Bogotá: Universidad Nacional de Colombia. 